\title{
CHRONIC TESTICULAR PAIN- A REVIEW OF LITERATURE
}

\author{
ASHRAF UDDIN MALLIK ${ }^{1}$, MD. WALIUL ISLAM ${ }^{2}$, MS ISLAM ${ }^{1}$, MD. SHAHIDUL ISLAM ${ }^{3}$, \\ AHM MANJURUL ISLAM ${ }^{3}$, ANWAR HOSSAIN ${ }^{3}$, ZINNAT HOSSAIN ${ }^{3}$ \\ ${ }^{1}$ Department of Urology, Prime Medical College and Hospital Rangpur, ${ }^{2}$ National Institute of Kidney Diseases and Urology, \\ Dhaka, ${ }^{3}$ Department Urology, Rangpur Medical College and Hospital, Rangpur.
}

\begin{abstract}
Objective: To review the current understanding of testicular pain, possible etiology and the available treatment options.

Materials and Methods: A literature search was made for abstract, original and review articles in the Medline, hand-searched relevant reference lists and conference proceedings and medical text book using the word "testicular pain" and orchialgia to find out possible etiology, understanding of testicular pain and treatment options.

Results: After literature search, it has found that management of testicular pain sometimes a challenging work for an Urologist. Management differs for the original etiology and for testicular and extra testicular causes. Sometimes symptomatic treatment improve the quality of life but in few cases surgery is mandatory for relieve of pain.

Conclusions: Management of chronic testicular pain depends on careful assessment of the causes. Relieve of symptoms is not always possible with analgesic only, in that case blockade of the spermatic cord will be helpful. Decision for surgery should not be undertaken quickly for there is no guarantee that there will always be resolution of pain For that reason patient should be counseled accordingly.
\end{abstract}

Key words: Testicular pain; extra testicular causes

Bangladesh J. Urol. 2012; 15(1): 18-20

\section{Introduction}

The appropriate definition of chronic testicular pain (CTP) is defined as a continuous or intermittent, unilateral or bilateral testicular pain for at lest 3 months or more in duration that significantly interferes with the daily activities of the patient so as to forces the patient to seek medical assistance. These types of patients used to go to multiple physicians during the course of disease for evaluation and better treatment. As a result, their frustration further increase, and for many patients is associated with anxiety about cancer, even patient's physician relationship detoriate. The etiology of chronic testicular pain is idiopathic in $25 \%$ of patients and sometimes varied ${ }^{1}$. CTP may arise at any age, but majority of patients are in $20-30$ years of age group. The desired goal of the management is to allow the patient to improve the quality of life without longtime use of NSAID. If the etiology of the pain is known, the

Correspondence: Dr. Ashraf Uddin Mullik, Department Urology, Prime Medical College and Hospital, Rangpur, E-mail ashrafmollik2004@yahoo.com treatment is satisfactory; consequently, if the cause detection is difficult, treatment is unsatisfactory. Sexual arousal that does not determine in ejaculation but can cause congestion in the vas, resulting in a dull aching sensation in the testis. This is sometimes referred as Blue balls, this is inconvenient but entirely harmless. This pain disappears, may be repeated. Post vasectomy chronic testicular pain may be due to functional obstruction of the vas or to spermatic granuloma. Up to $43 \%$ of men who undergo vasectomy develop post vasectomy pain syndrome; the cause is unknown ${ }^{4}$. In one study the histological analysis of 5-7 years post vasectomy vas of few patients those developed unremitting epididymal pain due to long standing vas obstruction. Other authors conducted retrospective studies using postal questionnaires and found $15-19 \%$ incidence of CTP in post vasectomy patients ${ }^{5}$.After several years of vasectomy surgery the diameter of the ejaculatory ducts often increase in size to counteract the fluid pressure inside. Among them about 5 to $43 \%$ of such man having post vasectomy testicular pain ${ }^{5}$. 
Formation of sperm granuloma or spermatoceles spares the testicle from damage secondary to increase fluid pressure. This type of granulomas, although benign lesions, may predispose a man to have testicular pain ${ }^{6}$. In normal condition cystic fluid is not infected. In infected cysts it has been found that the level of IL-6,IL-8, and TNF alpha is high. These findings indicate that local production proinflammatory cytokines are present in the epididymal cysts fluid, removal of cysts fluid might be helpful. Although not apparently reported in the literature we, along with others, have found that simple aspiration of small epididymal cysts with insertion of sclerosing substances can alleviate scrotal pain ${ }^{7}$. Chronic testicular pain can also be psychogenic, often relating to a history of sexual abuser or relationship stress. One study examining psychological conditions in men with chronic testicular pain found in $56 \%$ of the patients, nontesticular pain in $50 \%$, and chemical dependency in $27 \%{ }^{8}$

\section{Referred Pain}

Two types of pain have their origins in the genital organs : local and referred. The referred pain is common. Any organ that shares the same nerve supply with the scrotal contents can present with pain in this region. Pain arising for stone in the lower ureter may cause pain to scrotum or scrotal content. Pain for disc prolapsed or hip problem and neuropathy of the ilioinguinal or genitofemoral nerve is some of the secondary causes of chronic testicular pain. ${ }^{9}$.For diabetic neuropathy testicular pain has been recognized. Even after stoppage of imipramin intake used as an antidepressant agent may cause CTP 10,20. CTP in case of increased uric acid in blood is hypothesized that uric acid crystal deposit in testicular canaliculi or alteration in nerve ending has been suggested. Testicular angina has also been reported. ${ }^{11}$. In case of neural plasticity injury may result a change at all levels of the nervous system, so, pain message are amplified. In case of post injury or surgery, chronic pain syndrome is the development of sprouting between axons $^{12}$.

Treatment option of chronic testicular pain: A variety of procedures and surgical options may help to minimize or alleviate CTP. There are no evidence-based guidelines for CTP treatment and nonrandomized controlled trials to demonstrate the superiority over another. In the absence of any findings that require surgical intervention, start conservatively. NSAID help only a small percentage of patients with CTP and only for a short-period of time. All treatments recommendations are based on expert opinion derived from small cohort studies. We reviewed of the literature evaluating medical and surgical treatment for CTP ${ }^{12}$. Application of scrotal elevation with supportive undergarments to decrease venous congestion may help for pain. Advice patient to modify his seated posture to avoid scrotal pressure may relieve pain. If suspected epididymitis treat with appropriate antibiotics. Antibiotics have not been shown to decrease the severity of CTP and their use, unless clearly indicated, may lead to drug resistance .

Use of alpha adrenergic antagonist: For expelled out of any ductal contents smooth muscle construction induced by adrenergic neurotransmitters is needed. CTP might be related to functional obstruction/ spasm of vas deferens or epididymis. Human vas deferens has similar adrenoreceptor like prostatic smooth muscle receptors. So, use of alpha $1 \mathrm{~A}$ antagonist in vivo might relieve a possible obstruction spasm of the vas deferens. Therefore, clinically, drugs that modify the activity of prostatic smooth muscle should also affect the vas. CTP that fails to response with conservative treatment and wish to avoid the surgery, a trial with alpha adrenergic antagonist may apply on them ${ }^{13}$. In a few cases tricyclic antidepressants and gabapentin showed benefit for chronic pelvic pain syndrome and neuropathic pain. In another study group consisted with psychologist, anesthetist, physiotherapist and occupational therapist found improvement in less than $50 \%$ in $62 \%$ of men with CTP treated with gabapentin and $67 \%$ of men treated with nortriptyline. Another group of patients having post vasectomy testicular pain did not improve in pain relieve in $50 \%$ patients with either TCA or gabapentine therapy ${ }^{14}$.

Consider minimally invasive treatment: When conservative treatment fails, minimally invasive techniques may achieve good results by spermatic cord blocks with lidocane and methylprednisolone for a period of several months ${ }^{15}$. Next micro invasive technique is transrectal ultrasound-guided periprostatic anesthetic injection may provide short term relieve but long term results are not good ${ }^{16}$.If medical and minimal invasive therapy fail surgical options should be considered, although in all time surgery can not improve pain, in this situation it is important to discuss with the patient concern. Lastly, microsurgical denervation of the spermatic cord should be considered only for patients who have experienced temporary relieve from spermatic cord block and applied all conservative measures 17

Surgical treatment. Epididymectomy is considered only when pain is localized to the epididymis, as it is a testis-sparing procedure.Unilateral or bilateral 
epididymectomy may consider for CTP related to post vasectomy or chronic epididymitis. In one study symptomatic improvement ranged from $43 \%$ to $74 \%$ during 5.5 years follow-up. In another study $90 \%$ patients were satisfied with their choice to undergo the procedure 18. Vasectomy reversal and inguinal or scrotal orchiectomy should be considered if all other treatment modalities fail. The goal of orchiectomy is to relieve chronic testicular pain. In one study demonstrated that $90 \%$ of man who underwent unilateral epididymectomy for CTP required an orchiectomy to resolve pain ${ }^{12,19}$. Another study showed that $80 \%$ of patients continue to suffer testicular pain even after orchiectomy ${ }^{12}$.

\section{Conclusions}

CTP remains a challenge to the urologist. However, before going to any minimal or invasive procedure it should be distinguished epididymal and testicular pain with scrotal pain. Because testis has an abdominal origin and instead of sacral innervations testis has sympathetic innervations. If there is no somatic or iatrogenous cause, it suggests hypersensitivity to pain. A proper clinical examination needs to assess epididymal and testicular pain, which should be consider every aspect of the pain including its functional and emotional components. A multidisciplinary team approach is desirable to get highest benefit from available treatment option.

Conflict of Interest : None declared

\section{References}

1. Davis BE, Noble NJ, Weigel JW, Foret JD, Mebust WK. Analysis and management of chronic testicular pa Masarani M, Cox R. The e aetiology, pathophysiology and management of chronic orchialgia. Br J Urol Int. 2003; 91: 435-437.

2. Masarani M, Cox R. The e aetiology, pathophysiology and management of chronic orchialgia. $\mathrm{Br} \mathrm{J}$ Urol Int. 2003; 91:435-437.

3. Granitsiotis P, Kirk D. Chronic testicular pain: an overview. Eur Urol. 2004;45:430-436.

4. Jarow JP, Budin RE, Dym M, et al. Quantitative pathologic changes in the human testis after vasectomy. N Engl J Med. 1985;313:1252-1256.

5. Choe J, Kirkemo A. Questionnaire-based outcomes study of nononcological post- vasectomy complications. J Urol. 1996;155:1284-1286. in its management. Br J Urol. 1997; 79: 269-270.

6. Christiansen CG, Sandlow JI. Testicular pain following vasectomy: a review of postvasectomy pain syndrome. J Androl. 2003; 24: 293-298.
7. I. Kocak, M. Dundar, C. Yenisey, M. Serter, G. Gunaydin. Pro-inflammatory cytokine response of the fluid contents of spermatoceles and epididymal cysts. Andrologia 34 (2) (2002) (112 - 115

8. L.R. Schover. Psychological factors in men with genital pain. Cleve Clin. J. Med. 57 (8) (1990) 697 - 700) . 9. L.J. Fon, R.A. Spence. Sportsman's hernia. Br J. Surg. 87 (5) (2000) (545 - 552).

10. I.W. Campbell, D.J.C.B.F. Ewing, L.J.P. Duncan. Testicular pain sensasion in diabetic autonomic neuropathy. Br. Med. J. 2 (1974) (638 - 639).

11. J. Jara Rascon, G. Escribano Patino, F. Herranz Amo, I. Moncada Iribarren, C.Hernandez Fernandez. Testicular microlithiasis: diagnosis associated with orchialgia. Arch. Esp. Urol. 51 (1) (1998) (82 - 85)

12. R.A. Costabile, M. Hahn, D.G. McLeod. Chronic orchialgia in the pain prone patient: the clinical perspective. J. Urol. 146 (6) (1991) (1571 - 1574)

13. P. Granitsioti, C. Daly, D. Kirk, J.C. McGrath. Characterisation of post-junctional receptors along the length of the human vas deferens: Differences from the rodents. BJU Int. 83 (2000) (365)

14. Sinclair, A.M., Miller, B. and Lee, L.K. ( 2007) Chronic orchialgia: consider gabapentin or nortriptyline before considering surgery. Int J Urol 14:622-625.

15. Issa M, Hsiao K, Bassel Y, et al. Spermatic cord anesthesia block for scrotal procedures in the outpatient clinic setting. J Urol. 2004; 172: 23582361.

16. Zorn B, Rauchenwald M, Steers WD. Periprostatic injection of local anesthesia for relief of chronic orchialgia. J Urol. 1994;151:411,A735.

17. Levine LA, Matkov TG, Lubenow TR. Microsurgical denervation of the spermatic cord: a surgical alternative in the treatment of chronic orchialgia. $J$ Urol. 1996;155:1005-1007.

18. D.E. Padmore, R.W. Norman, O.H. Millard. Analyses of indications for and outcomes of epididymectomy. J. Urol. 156 (1) (1996) (95 - 96)

19. Davis B, Noble MJ, Weigel JD, et al. Analysis and management of chronic testicular pain. J Urol. 1990;143:936-939.

20. M. Perera, M.A. Khan. Testicular pain and swelling on withdrawal of mipramin. Br.J.Psychiatry 173 (1998)(268). 